'free at the point of delivery'.

In discussing the decline of the service and the acceleration towards crisis under the Thatcher government, Dr Iliffe predictably catalogues increased technology, altered definitions of illness, an aging population and increased professional activity as the difficulties to be tackled. It is perhaps disappointing that by concentrating on condemning the inadequacies of right-wing policy and the commercialisation of the health service, he misses an opportunity to question the underlying ethical trends, only making amends with a brief discussion on the dilemmas of screening for cervical cancer and ischaemic heart disease - both of which are easier and less productive in the articulate and demanding minority.

It is in the final section of the book that $\mathrm{Dr}$ Iliffe is most interesting, most stimulating and most disappointing. Basing his plans for a future health service on what he calls 'the gift relationship' between funding (from general taxation) and the delivery of health care, he seeks to explore a way of ironing out injustices. In this he preaches good socialism, but could just as well be preaching good Christianity or even humanism, as the ethical ground is not explored. Having defined funding, he then aims to set limits and establish priorities. Some of these priorities - patient participation, personal responsibility, and a debunking of the medical profession's domination of the system - could almost be lifted from between the lines of the Government's White Paper, but clearly the political starting point and possible end-points may not be the same!

Drawing on the Black Report (beloved of all left-of-centre doctors) he recommends the expansion of community care and the use of social service indicators to direct budgets - an area on which Working for Patients is predictably vague.

Taken overall, the suggestions for prioritisation of the service are sound, but Dr Iliffe does get into something of an ethical tangle over the value of such treatments as IVF. His advocacy of some sort of charging for the skiier who breaks a leg or the woman who 'desires' a child seems coloured by his political judgement that the development of IVF is as much about professional power, research and the control of beds as about an altruistic wish to contribute to the physical and psychological needs of the patient.

In the end, Steve Iliffe's book is rather unbalanced, possibly because of its origin in shorter magazine articles. The political analysis is skimpy (particularly when compared with a book like Steve Watkins's Medicine and Labour - The Politics of a Profession) and the proposed solutions need expanding and justifying.

Even so, if the NHS is to be turned inside-out, any well-considered contribution to the debate is valuable, and this book fulfills that purpose.

GORDON PARKER Occupational Physician, Lancaster Health Authority

\section{Sentenced to Hospital}

\section{Susan Dell and Graham Robertson 170 pages, Oxford, $£ 20.00$, Oxford University Press, 1988}

This well produced and clearly written book is one of the Institute of Psychiatry's Maudsley Monographs and is written by two of that institute's forensic psychiatry section lecturers. It is based upon a study of the 117 men detained in April 1982 at Broadmoor Hospital under the legal category of psychopathic disorder. The first half of the book relates to a control group of patients admitted as mentally ill (matched only for length of stay and the Section of the Mental Health Act, 1959, under which the patient was admitted).

Despite the thorough nature of the study (there are 27 tables in the book), the findings for the mentally ill patients are generally unremarkable. Patients and staff tended to agree that the patients were ill ( 87 per cent with the diagnosis of schizophrenia) and that treatment was of value. Consultant psychiatrists were able to consider a patient's suitability for discharge in terms of his recovery. One striking finding, however, was that these doctors believed that only 28 per cent of the mentally ill group currently required Broadmoor's maximum security.

The men admitted to Broadmoor with a 'psychopathic disorder', however, are, by definition, not mentally ill and it is clear that those responsible for their 'treatment' face a considerable dilemma. Few received medication, but many of the men, at some time, received psychotherapy. Some valued this experience highly but others viewed it as coercive. 'They want to change you... the system wants you to agree with everything the doctor says about treatment... I want to get out of Broadmoor, so I agree with them. I play the game'. The patients believed that to be discharged, 'you have to serve the right length of time'. The consultants resisted the suggestion that there is a 'time for crime' but the study presents convincing evidence to the contrary.

The authors point out that it was the Butler Committee which stated that 'psychopathic disorder is no longer a useful or meaningful concept', a claim which this study supports. At best the medicalisation of certain offenders and their admission as 'psychopaths' to Special Hospitals allows them to serve their time in a better environment than prison ('more comfortable, less restrictive and better pay') and to have access to help such as psychotherapy. At worst, admission as a 'patient' can place a man who maintains his innocence in the situation where his release is dependent upon his responding to treatment which means accepting, understanding and then changing the behaviour which led to the offence he claims not to have committed.

Dell and Robertson propose that in future psychopathic offenders should only be voluntarily transferred to Special Hospitals from prison. Doctors would then no longer have the inappropriate task of determining the length of a man's sentence. The authors do not, however, fully explore the logical consequence of accepting their arguments: people who are not ill should not be admitted to hospital. Surely it should be possible to provide decent conditions in prison and to have there access to psychotherapy and other forms of help. Curiously the authors make no reference to Grendon Underwood Prison where this has been attempted.

The Health Advisory Service in its report on Broadmoor (1988) advised: 'The DHSS should review the role of Broadmoor Hospital in association with the three other Special Hospitals and draw up a strategic plan for their corporate functioning in association with Regional Secure Units, and hospital facilities offering lower levels of security elsewhere'. Sentenced to Hospital should be required reading in the Department of Health (and the Home Office). It would be nice to be able to believe that this book would be the final nail in the coffin of that old fraud 'psychopathic disorder'.

G P PULLEN

Consultant Psychiatrist Littlemore Hospital, Oxford 